\title{
Eficácia da espectroscopia por ultrassom e do congelamento na avaliação da composição química do leite
}

\author{
Maura Frare MENEGON ${ }^{1}$, Claudineli Cassia Bueno da ROSA², Carmen WOBETO3 \\ Marcia Rodrigues Carvalho OLIVEIRA ${ }^{1}$, Henrique Melo da SILVA ${ }^{1}$, Andrea Betina DONADIA ${ }^{1}$, \\ Letícia MENEGAZZO ${ }^{1}$, Walter Bedon GALLARDO ${ }^{1}$, André Soares de OLIVEIRA ${ }^{1,2^{*}}$ \\ ${ }^{1}$ Dairy Cattle Research Lab, Universidade Federal de Mato Grosso, Sinop, MT, Brasil. \\ (ORCID: 0000-0001-8103-0460; 0000-0001-8321-4394; 0000-0002-8112-9919; 0000-0002-8434-4278; \\ 0000-0002-8951-8310; 0000-0002-5992-3454) \\ 2Instituto de Ciências Agrárias e Ambientais, Universidade Federal de Mato Grosso, Sinop, MT, Brasil. \\ (ORCID: 0000-0002-6478-8162) \\ ${ }^{3}$ Instituto de Ciências Naturais, Humanas e Sociais, Universidade Federal de Mato Grosso, Sinop, MT, Brasil. \\ (ORCID: 0000-0002-8645-5203) \\ *E-mail: andresoli@uol.com.br (ORCID: 0000-0002-5992-3454)
}

Recebido em 27/05/2019; Aceito em 23/09/2019; Publicado em 04/02/2020.

\begin{abstract}
RESUMO: Objetivou-se avaliar o método de espectroscopia por ultrassom (EU) e o efeito do congelamento do leite nas análises de gordura e proteína do leite de vaca. Cem amostras foram analisadas imediatamente após a coleta em tanque de expansão (in natura), congeladas a $-20^{\circ} \mathrm{C}$ por 30 dias e novamente analisadas por métodos oficiais (gordura por butirômetro de Gerber e proteína por micro-Kjeldahl) e por EU. Observou-se efeito de interação $(P<0,01)$ entre o método analítico e congelamento do leite. A EU superestimou $(P<0,01)$ o teor de gordura e subestimou $(P<0,01)$ o teor de proteína no leite in natura ou congelado. O congelamento não afetou $(P=0,15)$ o teor de gordura obtido pelo método oficial, mas reduziu o teor de gordura $(P<0,01)$ obtido com a EU. O congelamento aumentou $(P<0,01)$ o teor de proteína obtido pelo método oficial, mas reduziu $(P<$ $0,01)$ quando obtido por EU. Os teores de gordura e proteína do leite obtidos pelo método de EU são divergentes daqueles obtidos por métodos oficiais, independente da amostra ser in natura ou congelada.
\end{abstract}

Palavras-chave: método analítico; análise química; correlação.

\section{Efficacy of ultrasonic spectroscopy and freezing in evaluation} of milk chemical composition

\begin{abstract}
The objective was to evaluate the ultrasound spectroscopy (US) method and the effect of milk freezing on the cow's milk fat and protein analysis. One hundred samples were collected from one milk tank, immediately analyzed, and frozen at $-20^{\circ} \mathrm{C}$ for 30 days and analyzed again by official method (fat: Gerber butyrometer, protein: micro-Kjeldahl) and US. It was observed effect of interaction $(\mathrm{P}<0.01)$ between analytical method and milk freezing. Ultrasound spectroscopy overestimated milk fat content and underestimated milk protein content on in natura or frozen. The milk freezing for 30 days did not affect the milk fat content obtained by official method $(\mathrm{P}=0.15)$, but it reduced the milk fat content $(\mathrm{P}<0.01)$ obtained by US. The milk freezing increased $(\mathrm{P}<0.01)$ the milk protein content obtained by official method, but reduced $(\mathrm{P}<0.01)$ when obtained from US. The milk fat and protein content obtained by US are different from those obtained by official methods, regardless of the sample is in natura or frozen.
\end{abstract}

Keywords: analytical method; chemical analysis; correlation.

\section{INTRODUÇÃO}

O conhecimento da composição química do leite cru é fundamental nas políticas oficiais de controle da qualidade do produto, nos programas de pagamento ao produtor por qualidade, nos programas de melhoramento genético de rebanhos, na determinação das exigências nutricionais de vacas leiteiras e no monitoramento do estado nutricional e clínico dos animais. Normalmente, este monitoramento é realizado por laboratórios oficiais credenciados junto ao Ministério da Agricultura e Pecuária (MAPA), e nos estabelecimentos beneficiadores de leite.

Há vários métodos bem estabelecidos para as determinações físico-químicas, dentre os quais aqueles adotados pela legislação vigente como sendo oficiais, como o método de Gerber para gordura e Kjeldahl para proteína (ISO; IDF, 2001; BRASIL, 2018). Os métodos oficiais exigem tempo, mão de obra treinada e requerem reagentes caros e perigosos para sua execução.

A Instrução normativa No 77 (BRASIL, 2018) estabelece que tais métodos poderão ser substituídos por outros métodos de controle operacional, desde que sejam conhecidos seus desvios e correlações em relação aos respectivos métodos de referência. Assim, o desenvolvimento e avaliação de métodos alternativos acurados, mais rápidos e de menor custo podem proporcionar benefícios à cadeia produtiva. 
As técnicas de análise por infravermelho próximo para análise do leite foram aperfeiçoadas nos últimos 30 anos, permitindo-se hoje analisar um número elevado de amostras com acurácia e precisão (IDF, 1999). Atualmente, representa o principal método usado nos laboratórios oficiais de controle da qualidade de leite no Brasil e no mundo. Porém, os elevados custos de aquisição dos equipamentos ainda limita sua adoção em diversos laboratórios, nos estabelecimentos beneficiadores e nas propriedades rurais.

O método de espectroscopia por ultrassom (EU) representa uma alternativa para determinação físico-química do leite, em razão do menor custo do equipamento em relação à técnica por infravermelho. A tecnologia ultrassônica foi desenvolvida a partir do princípio fundamental de que a matéria é capaz de absorver o som, atenuando-o ou alterando sua velocidade, permitindo estabelecer associação com composição física e química (BUCKIN et al., 2003; DUKHIN et al. 2003; PONSANO et al., 2007).

Em estudos preliminares com número limitado de amostras têm indicado alta correlação dos valores de gordura e proteína obtidos pelo método ultrassom com os procedimentos oficiais para análise do leite cru, embora com divergências nas estimativas das médias (PONSANO et al., 2007; VENTUROSO et al., 2007). Assim, é necessário investigar o potencial de uso do método de espectroscopia por ultrassom para análises dos teores de gordura e proteína do leite.

As análises do leite por métodos oficiais ou alternativos têm sido feitas em amostras in natura ou conservadas com conservante e resfriada em curto período. Todavia, em situações de experimentação animal ou nas propriedades rurais, a necessidade de análise imediata do leite in natura representa um inconveniente operacional.

O congelamento das amostras para posterior análise pode facilitar os procedimentos experimentais e analíticos. Entretanto, o congelamento do leite pode provocar a perda da estabilidade das micelas de caseína e a coalescência dos glóbulos de gordura (WALSTRA et al., 2006). Desta forma, pode afetar as análises principalmente por métodos físicos como a espectroscopia por ultrassom.

Como nas análises por métodos químicos (Gerber e Kjeldahl) ocorre ação de ácidos fortes nas amostras, nossa hipótese é que os efeitos do congelamento podem ser menos acentuados nestes métodos. Porém, os efeitos do congelamento sobre a composição química do leite ainda são inconsistentes, sendo observados aumento nos teores de gordura e proteína no leite em alguns estudos (WEESE et al., 1969) e ausência de efeitos do congelamento em outros estudos (ZHANG et al., 2006; CURI; BONASSI, 2007; OLIVEIRA et al., 2002). Desta forma, ainda é necessário investigar os efeitos do congelamento sobre as estimativas dos teores de gordura e proteína no leite.

A nossa hipótese é que o método de espectroscopia por ultrassom estima os teores de gordura e proteína do leite de vaca com acurácia e precisão, e pode ser usado como alternativa aos métodos oficiais. Além disso, o congelamento do leite não afeta as estimativas dos teores de gordura e proteína do leite obtidos por métodos químicos oficiais.

Objetivou-se avaliar o método de espectroscopia por ultrassom e o efeito do congelamento do leite nas análises de gordura e proteína do leite.

\section{MATERIAL E MÉTODOS}

O experimento foi conduzido no Laboratório de Pecuária Leiteira. Foram coletadas 100 amostras de $200 \mathrm{~mL}$ de leite $\mathrm{cru} / \mathrm{cada}$, logo após a primeira ordenha do dia, em um tanque de resfriamento de um sistema comercial de produção de leite.

Imediatamente antes das coletas o leite armazenado no tanque foi submetido à agitação por 5 minutos. Após a coleta, as amostras foram mantidas em caixa isotérmica $e$ transportadas imediatamente até laboratório (em 30 minutos), para análise imediata dos teores de gordura e proteína pelos métodos oficiais e espectroscopia por ultrassom, e posterior congelamento $\left(-20^{\circ} \mathrm{C}\right)$ durante 30 dias. Após o período de 30 dias, as amostras foram descongeladas em banho-maria $\left(25^{\circ} \mathrm{C}\right)$ por duas horas, de maneira a manter a temperatura do leite próxima aquela obtida com o leite in natura $\left(20-25^{\circ} \mathrm{C}\right)$.

Todas as análises de gordura e proteína foram feitas em triplicata. As análises de gordura, denominado método oficial, foram realizadas usando o método do butirômetro de Gerber (ISO; IDF, 2008). As análises de proteína bruta, denominado método oficial, foram realizadas usando o método micro-Kjeldahl (ISO; IDF, 2001) adotando-se o fator de conversão de nitrogênio em proteína bruta de 6,38. A análise por espectroscopia por ultrassom foi feita com o equipamento calibrado de fábrica para leite de vaca (Master Classic Complete, Akso Produtos Eletrônicos, São Leopoldo, RS, Brasil), conforme manual de uso fornecido pelo fabricante.

Os efeitos do método (oficial versus espectroscopia por ultrassom) e do congelamento do leite foram analisados como delineamento inteiramente casualizado, com o efeito do método repetido no tempo (in natura ou congelado), conforme seguinte modelo geral:

$$
\mathrm{Yij}=\mu+\mathrm{Ci}+\mathrm{Mj}+\mathrm{Ci} \times \mathrm{Mj}+\mathrm{eij}
$$

em que: Yij = observação na amostra submetida in natura ou congelada, analisada por métodos oficiais e por ultrassom; $\mu=$ média geral; $\mathrm{Ci}=$ efeito do congelamento $(1=$ leite in natura e $2=$ leite congelado); $\mathrm{Mi}=$ efeito do método dentro de cada condição do leite $(1=$ oficial e $2=$ ultrassom $) ; \mathrm{Ci} \times \mathrm{Mj}=$ efeito de interação do congelamento e método de análise; eij = variação aleatório residual $(0 ; \sigma 2)$. Foi adotado nível de $5 \%$ de probabilidade para o erro tipo I.

Adicionalmente, foi ajustado de regressão linear simples entre os valores obtidos da técnica de ultrassom com os valores obtidos pelos métodos oficiais, para verificar o grau de correlação e potencial de uso de equações de calibração.

\section{RESULTADOS}

A estatística descritiva dos teores de proteína bruta e gordura do leite in natura ou submetido ao congelamento por 30 dias, obtidos por métodos oficiais ou por espectroscopia de ultrassom está apresentada na Tabela 1.

Observou-se efeito de interação $(P<0,01)$ entre o método analítico (oficial versus espectroscopia por ultrassom) e congelamento do leite sobre os teores de gordura e proteína bruta. Assim, os efeitos de método e congelamento foram desmembrados (Figuras 1 e 2). A espectroscopia por ultrassom superestimou em 0,51 pontos percentuais $(P<$ $0,01)$ o teor de gordura no leite in natura e em 0,36 pontos 
percentuais $(P<0,01)$ no leite submetido ao congelamento (Figura $1 \mathrm{~A}$ ). Além disso, os teores de gordura obtido por espectroscopia por ultrassom apresentaram maior coeficiente de variação que aqueles obtidos pelo método oficial (Tabela 1), principalmente com leite in natura, indicando menor precisão analítica da espectroscopia por ultrassom.

Tabela 1. Estatística descritiva dos teores de proteína bruta e gordura do leite in natura ou submetido ao congelamento por 30 dias, obtidos por métodos oficiais ou por espectroscopia de ultrassom (ultra) ( $\mathrm{n}=100)$.

Table 1. Descriptive statistics of crude protein and milk fat in natura or frozen for 30 days, obtained by official methods or ultrasound (ultra) spectroscopy $(\mathrm{n}=100)$.

\begin{tabular}{lccccc}
\hline \multirow{2}{*}{ Item } & \multicolumn{2}{c}{ In natura } & & \multicolumn{2}{c}{ Congelado } \\
\cline { 2 - 3 } \cline { 5 - 6 } Oficial & Ultra & & Oficial & Ultra \\
\hline Gordura, \% & 3,19 & 3,70 & & 3,10 & 3,46 \\
Média & 3,13 & 3,03 & & 3,07 & 3,43 \\
Mediana & 2,67 & 2,65 & & 2,27 & 2,58 \\
Mínimo & 3,73 & 4,15 & & 3,73 & 4,36 \\
Máximo & 0,27 & 0,50 & & 0,34 & 0,41 \\
Desvio padrão & 8,62 & 13,53 & & 10,84 & 11,85 \\
CV (\%) & & & & & \\
Proteína bruta, \% & 3,13 & 2,84 & & 3,46 & 2,59 \\
Média & 3,17 & 2,82 & & 3,48 & 2,54 \\
Mediana & 2,72 & 2,65 & & 2,75 & 2,43 \\
Mínimo & 3,69 & 3,70 & & 3,72 & 3,16 \\
Máximo & 0,30 & 0,15 & & 0,18 & 0,16 \\
Desvio padrão & 9,54 & 5,31 & & 5,23 & 6,35 \\
CV (\%) & & & & & \\
\hline
\end{tabular}

${ }^{1} \mathrm{CV}=$ Coeficiente de variação $(\%)$.
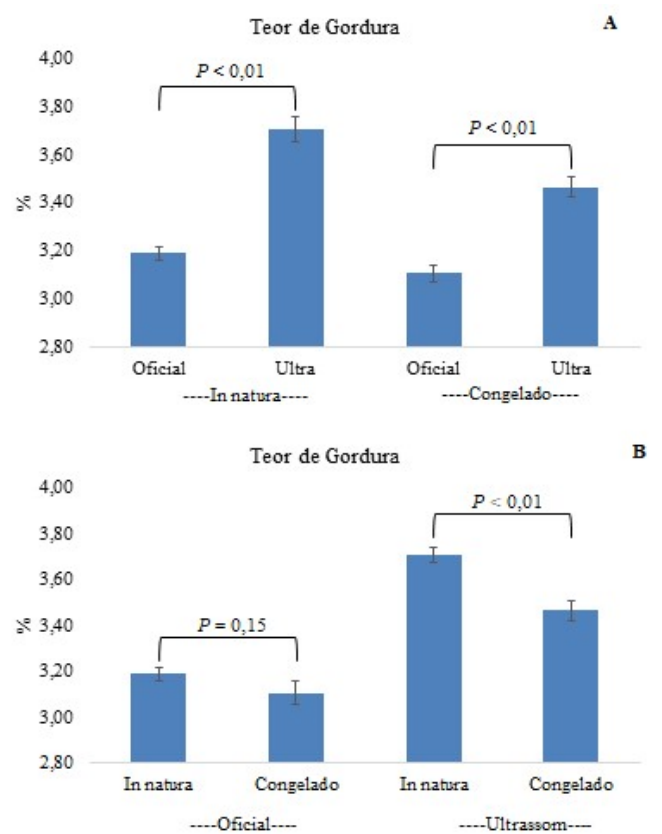

Figura 1. Efeito do método (oficial ou por espectroscopia de ultrassom, A) e do congelamento do leite (B) sobre os teores de gordura do leite de vaca. Valores médios e erro padrão da média. Figure 1. Effect of the method (official or by ultrasound spectroscopy, A) and milk freezing (B) on the fat content of cow's milk. Mean values and standard error of the mean.

O congelamento do leite por 30 dias não afetou $(P=0,15)$ o teor de gordura do leite obtido pelo método oficial (butirômetro de Gerber), mas reduziu o teor de gordura $(P<$ 0,01 ) obtido com a espectroscopia por ultrassom (Figura 1 B). O coeficiente de correlação (r) de 0,82 entre teor de gordura obtido por espectroscopia por ultrassom com método oficial especificamente no leite in natura. $\mathrm{O}$ coeficiente de correlação entre teor de gordura obtido por espectroscopia por ultrassom com método oficial no leite congelado foi apenas de 0,49 (Figura 3).

A espectroscopia por ultrassom subestimou em 0,29 pontos percentuais $(P<0,01)$ o teor de proteína bruta no leite in natura e em 0,87 pontos percentuais $(P<0,01)$ no leite submetido ao congelamento (Figura $1 \mathrm{~B}$ ). Todavia, os teores de proteína bruta obtidos por espectroscopia por ultrassom apresentou menor coeficiente de variação do que por método oficial (Tabela 1) com leite in natura.

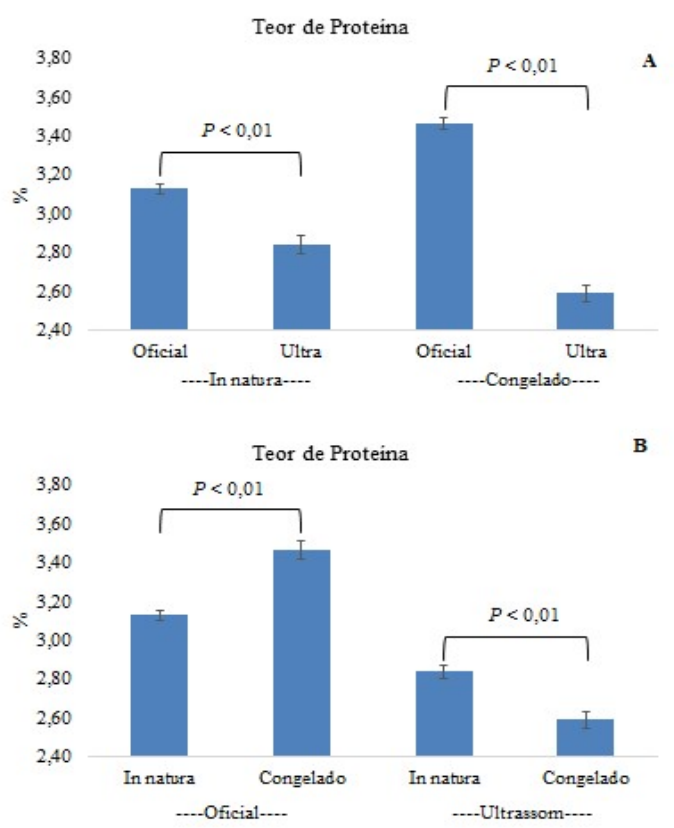

Figura 2. Efeito do método (oficial ou por espectroscopia de ultrassom, A) e do congelamento do leite (B) sobre os teores de proteína do leite de vaca. Valores médios e erro padrão da média. Figure 2. Effect of the method (official or by ultrasound spectroscopy, A) and milk freezing (B) on the levels of cow's milk protein. Mean values and standard error of the mean.

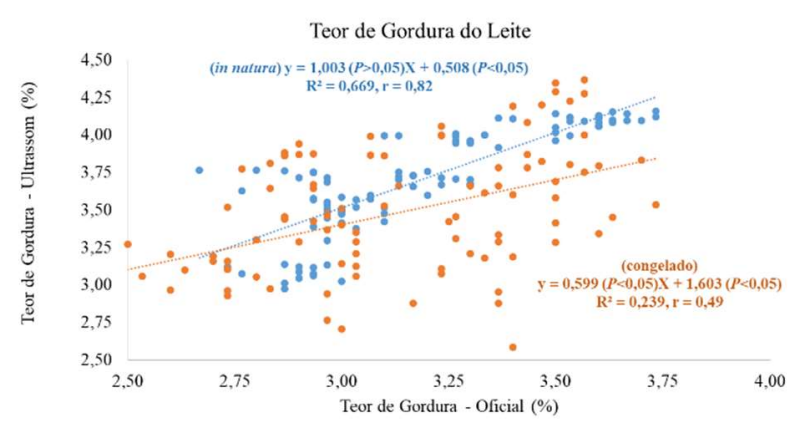

Figura 3. Relação entre o teor de gordura do leite obtido por espectroscopia de ultrassom e por método oficial (Gerber) em amostras de leite in natura ou submetidas ao congelamento.

Figure 3. Relationship between the fat content of the milk obtained by ultrasound spectroscopy and the official method (Gerber) in samples of milk in natura or frozen.

Diferente ao observado para o teor de gordura (leite in natura, Figura 3), o coeficiente de correlação entre teor de proteína bruta obtida por espectroscopia por ultrassom com método oficial (Kjeldahl) no leite in natura foi de 0,40 e no leite submetido ao congelamento de 0,26 (Figura 4), indicando limitações para o desenvolvimento de equações de 
calibração para a espectroscopia por ultrassom para estimativa do teor de proteína do leite.

Diferente ao observado com o teor de gordura obtido pelo método oficial, o congelamento do leite por 30 dias aumentou $(P<0.01)$ o teor de proteína do leite obtido pelo método oficial (Kjeldahl), mas reduziu o teor de proteína ( $P$ $<0.01$ ) obtido com a espectroscopia por ultrassom (Figura 2 B).

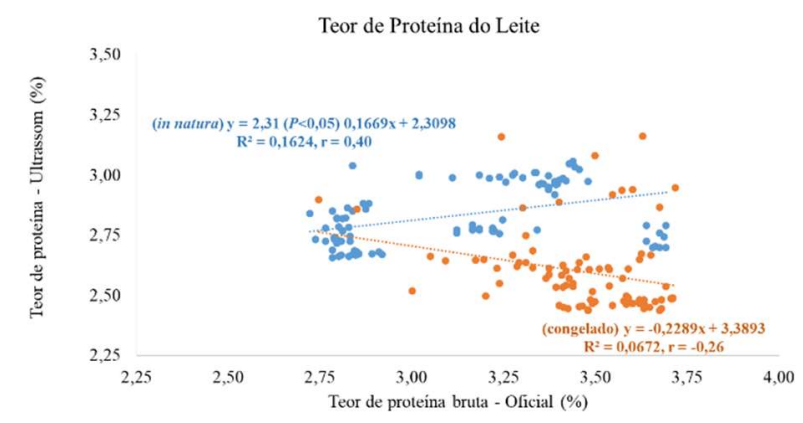

Figura 4. Relação entre o teor de proteína bruta do leite obtido por espectroscopia de ultrassom e por método oficial (Kjeldahl) em amostras de leite in natura ou submetidas ao congelamento.

Figure 4. Relationship between the crude protein content of milk obtained by ultrasound spectroscopy and by official method (Kjeldahl) in samples of milk in natura or frozen.

\section{DISCUSSÃO}

Nossos resultados corroboram com os de Ponsano et al. (2007) e Venturoso et al. (2007) sobre divergências nas estimativas dos teores de gordura do leite de vaca obtido com espectroscopia por ultrassom e o método oficial (Gerber). Todavia, estes pesquisadores observaram que a espectroscopia por ultrassom subestimou os teores de gordura enquanto nós observamos superestimava. Como a espectroscopia por ultrassom baseia-se na avaliação do comportamento das ondas sonoras de alta frequência ao se propagarem através de uma amostra, e sua posterior calibração com os parâmetros do leite obtidos por métodos oficiais, divergências quanto às equações de calibração usadas nos equipamentos de ultrassom podem explicar essas diferenças. Porém, observou-se coeficiente de correlação (r) de 0,82 entre teor de gordura obtido por espectroscopia por ultrassom com método oficial especificamente no leite in natura (Figura 3), indicando potencial de uso da espectroscopia por ultrassom mediante desenvolvimento de equações de calibração com banco de dados mais abrangentes.

O congelamento do leite pode provocar a coalescência dos glóbulos de gordura devido à formação de cristais de gelo e liberação das membranas fosfolipídicas dos glóbulos de gordura que previnem sua agregação (WALSTRA et al., 2006). Como a espectroscopia por ultrassom é um método físico baseado na avaliação do comportamento da propagação (reflexão, refração ou difração) das ondas sonoras de alta frequência na amostra (MILES et al., 1990), nossa hipótese é que o aumento da coalescência dos glóbulos de gordura com o congelamento provocou alteração no comportamento das ondas ultrassônicas na amostra e, consequentemente, na estimativa do teor de gordura do leite.

Por outro lado, a ausência de efeito de congelamento sobre os teores de gordura obtido com o método oficial pode estar associada ao fundamento analítico. O método de butirômetro de Gerber envolve uma reação de hidrólise ácida com ácido sulfúrico juntamente com álcool amílico, o que permite separar proteínas e carboidratos ligados aos glóbulos de gordura (ISO; IDF, 2008).

Desta forma, nossa hipótese é que a hidrólise ácida e a separação dos glóbulos de gordura atenuam os efeitos do congelamento sobre a coalescência dos glóbulos de gordura, permitindo-se obter estimativas do teor de gordura do leite submetido ao congelamento semelhante ao leite in natura. Porém, diferente ao observado com leite in natura, o coeficiente de correlação entre teor de gordura obtido por espectroscopia por ultrassom com método oficial no leite congelado foi apenas de 0,49 (Figura 3), indicando limitações para o desenvolvimento de equações de calibração para espectroscopia por ultrassom com leite submetido ao congelamento.

Nossos resultados também corroboram com os de Ponsano et al. (2007) e Venturoso et al. (2007) sobre divergências nas estimativas dos teores de proteína bruta do leite de vaca obtidos com espectroscopia por ultrassom e o método oficial (Kjeldahl). Entretanto, estes pesquisadores observaram que a espectroscopia por ultrassom superestimou os teores de proteína enquanto nós observamos subestimativa. Semelhante às razões anteriormente apresentadas para gordura do leite, como a espectroscopia por ultrassom baseia-se na avaliação do comportamento das ondas sonoras de alta frequência ao se propagarem através de uma amostra, e sua posterior calibração com os parâmetros do leite obtidos por métodos oficiais, divergências quanto às equações de calibração usadas nos equipamentos de ultrassom podem explicar as diferenças entre os estudos. Além disso, deve ser considerado potenciais efeitos de interações entre método e o analista, o que também pode ter interferido nas divergências observadas.

O congelamento do leite pode provocar desestabilização da estrutura molecular da caseína, causando perdas de estabilidade, dissociação micelar e precipitação (DESAI et al., 1961). Todavia, como o método de Kjeldahl baseia-se na obtenção dos teores de nitrogênio total da amostra (fontes proteicas e não proteicas) após digestão ácida, destilação alcalina e titulação ácida (IDF, 1993), o aumento nas estimativas dos teores de nitrogênio total não deveria ser esperado com o congelamento.

Desta forma, as razões da interferência do congelamento do leite nas estimativas dos teores de proteína bruta do leite ainda necessitam ser investigadas. Por outro lado, a precipitação das proteínas causada pelo congelamento pode ter afetado o comportamento da propagação (reflexão, refração ou difração) das ondas sonoras de alta frequência na amostra de leite (MILES et al., 1990), e consequentemente alterado a estimativa do teor de proteína do leite.

\section{CONCLUSÕES}

Os teores de gordura e proteína do leite obtidos pelo método de espectroscopia por ultrassom são divergentes daqueles obtidos por métodos oficiais, independente da amostra ser in natura ou submetida ao congelamento. O congelamento do leite não afeta os teores de gordura do leite obtido pelo método oficial (Gerber), mas reduz quando obtidos pelo método de espectroscopia por ultrassom. O congelamento do leite afeta os teores de proteína do leite obtidos pelo método oficial (Kjeldahl) ou por espectroscopia 
de ultrassom. O método de espectroscopia por ultrassom estima os teores de gordura do leite in natura com correlação positiva de 0,82 com método oficial (Gerber) e assim, apresenta potencial de uso para obtenção dos teores de gordura, desde que se ajustem equações de calibração com banco de dados abrangentes.

\section{AGRADECIMENTOS}

A Fundação de Amparo à Pesquisa do Estado de Mato Grosso pela concessão da bolsa de mestrado (009/2013) e concessão de recursos para execução do trabalho (PRONEN 2011, Processo 483724). Ao Conselho Nacional de Desenvolvimento Cientifico e Tecnológico pela concessão de bolsa de produtividade em pesquisa (Prof. André Soares de Oliveira, Processo 305826/2013-1).

\section{REFERÊNCIAS}

BRASIL. Instrução Normativa $\mathbf{n}^{\circ} \mathbf{7 7}$ de 26 de Novembro de 2018. Estabelece os critérios e procedimentos para a produção, acondicionamento, conservação, transporte, seleção e recepção do leite cru em estabelecimentos registrados no serviço de inspeção oficial. Diário Oficial da União, N. 230, Brasília, 30 Novembro 2018. Seção 1, p.10-17.

BUCKIN, V.; O’DRISCOLL, B.; SMYTH, C.; ALTING, A. C.; VISSCHERS, R. W. Ultrasonic spectroscopy for material analysis: recent advances. Spectroscopy Europe, v. 15, n. 1, p. 20-25, 2003.

CURI, R. A.; BONASSI, I. A. Elaboração de um queijo análogo ao Pecorino Romano produzido com leite de cabra e coalhada congelados. Ciência e Agrotecnologia, Lavras, v. 31, n. 1, p. 171-176, 2007. DOI: http://dx.doi.org/10.1590/S1413-70542007000100025

DESAI, I. D.; T.A.NICKERSON, T. A.; JENNINGS, W. G. Stability of Frozen Milk. Journal of Dairy Science, Champaign, v. 44, p. 215-221, 1961.

DUKHIN, A.S.; GOETZ, P.J.; TRAVERS, B. Ultrasound for characterizing liquid based food products. 1 Acoustic spectroscopy. Mount Kisco: Dispersion Technology, 2003. $26 \mathrm{f}$.

IDF_INTERNATIONAL DAIRY FEDERATION. Milk. Determination of the total nitrogen content. Bruxelas: IDF, 1993. Standard 20B.

IDF_INTERNATIONAL DAIRY FEDERATION. Milk. Determination and evaluation of the overall accuracy of indirect methods of milk analysis application to calibration procedure and quality control in the dairy laboratory. Bruxelas: IDF, 1999. Standard 128A.
IOS_INTERNATIONAL ORGANIZATION FOR STANDARDIZATION; IDF_INTERNATIONAL DAIRY FEDERATION. Milk - Determination of fat content. 2008. Genebra: ISO 2446:2008(E). Bruxelas: IDF, 2008. 226 p.(E).

IOS_INTERNATIONAL ORGANIZATION FOR STANDARDIZATION; IDF_INTERNATIONAL DAIRY FEDERATION. Milk - Determination of nitrogen content - Part 1: Kjeldahl method. 2001. Genebra: Bruxelas, IDF, 2001. 20 p.

MILES, C. A.; SHORE, D.; LANGLEY, K. R. Attenuation of ultrasound in milks and creams. Ultrasonics, Surrey, v. 28 , n. 6 , p. 394-400, 1990. DOI: https://dx.doi.org/10.1016/0041-624X(90)90063-T

OLIVEIRA, J. M.; HIANE, P. A.; RAMOS, M. I. L. Características físicoquímicas do leite de cabra pasteurizado e congelado, produzido em Campo GrandeMS. Revista Higiene Alimentar, São Paulo, v. 16, n. 102-103, p. 107-111, 2002.

PONSANO, E. H. G.; PERRI, S. H. V.; MADUREIRA, F. C. P. PAUlinO, R. Z.; CAMOSSI, L. G. Correlação entre métodos tradicionais e espectroscopia de ultra-som na determinação de caracteristicas fisico-quimicas do leite. Arquivo Brasileiro de Medicina Veterinária e Zootecnia, São Luiz, v. 59, n. 4, p. 1052-1057, 2007. DOI: http://dx.doi.org/10.1590/S010209352007000400035

VENTUROSO, R. C.; ALMEIDA, K. E.; RODRIGUES, A. M. A. M.; Damin, M. R.; Oliveira, M. N. Determinação da composição físico-química de produtos lácteos: estudo exploratório de comparação dos resultados obtidos por metodologia oficial e por ultra-som. Revista Brasileira de Ciências Farmacêuticas, São Paulo, v. 43, n. 4, p. 607-613, 2007. DOI: http://dx.doi.org/10.1590/S151693322007000400014

WALSTRA, P.; WOUTERS, J.T.M.; GEURTS, T.J. Dairy science and technology. 2. ed. United States of America: TAYLOR \& FRANCIS, 2006. 763 p.

WEESE, S.J.; BUTCHER, D.F.; and THOMAS, R.O. Effect of freezing and length of storage on milk properties. Journal of Dairy Science, Champaign, v. 52, n. 11, p. 1724-1726, $1969 . \quad$ DOI: https://dx.doi.org/10.3168/jds.S0022-0302(69)86833-5

ZHANG, R. H.; MUSTAFA, A. F.; NG-KWAI-HANG, K. F.; ZHAO, X. Effects of freezing on composition and fatty acid profiles of sheep milk and cheese. Small Ruminant Research, Amsterdam, v. 64, n. 3, p. 203-210, 2006.

DOI: https://dx.doi.org/10.1016/j.smallrumres.2005.04.025 